\title{
DFT studies on the magnetic exchange across the cyanide bridge
}

\author{
Mihail Atanasov ${ }^{a, b, c}$, Peter Comba ${ }^{b}$ and Claude A. Daul ${ }^{c}$
}

\footnotetext{
${ }^{a}$ Institute of General and Inorganic Chemistry, Bulgarian Academy of Sciences, Acad. Georgi Bontchev Str. Bl.11, 1113 Sofia, Bulgaria

${ }^{\mathrm{b}}$ Universität Heidelberg, Anorganisch-Chemisches Institut, Im Neuenheimer Feld 270, D-69120 Heidelberg, Germany

${ }^{\mathrm{c}}$ Département de Chimie, Departement für Chemie, Ch.du Musée 9, CH-1700 Fribourg, Switzerland
}

\section{Supporting Information}


Table S1. Effects of the functional, of the basis set and of the replacement of terminal CN ligands by $\mathrm{NH}_{3}$ on the $\mathrm{Cu}^{\mathrm{II}}-\mathrm{NC}-\mathrm{Cr}^{\mathrm{III}}$ exchange coupling constant and on the spin populations $\rho$ on $\mathrm{Cu}, \mathrm{Cr}$ and the bridging $\mathrm{C}$ and $\mathrm{N}$ atoms as calculated by the program ORCA.

\begin{tabular}{|c|c|c|c|c|c|c|}
\hline Species & $\begin{array}{l}\text { Charge } \\
\text { compensation }\end{array}$ & Basis & Functional & $\mathrm{E}_{\mathrm{BS}}-\mathrm{E}_{\mathrm{HS}}$ & $\mathrm{J}_{\mathrm{BS}}$ & $\rho(\mathrm{Cr}) \quad \rho(\mathrm{Cu}) \quad \rho(\mathrm{C}) \quad \rho(\mathrm{N})$ \\
\hline $\mathrm{CuNCCrCN}\left(\mathrm{NH}_{3}\right)_{4}$ & none & SVP & B3LYP & 4.8 & 3.2 & $\begin{array}{llll}3.250 & 0.579 & -0.109 & 0.075(\mathrm{M}) \\
3.037 & 0.593 & -0.052 & 0.065(\mathrm{~L})\end{array}$ \\
\hline $\mathrm{CuNCCrCN}\left(\mathrm{NH}_{3}\right)_{4}$ & none & TZVP & B3LYP & 5.7 & 3.8 & $\begin{array}{llll}3.250 & 0.573 & -0.118 & 0.077(\mathrm{M}) \\
3.019 & 0.615 & -0.050 & 0.064(\mathrm{~L})\end{array}$ \\
\hline $\mathrm{CuNCCrCN}\left(\mathrm{NH}_{3}\right)_{4}$ & none & SVP & PW91 & 8.2 & 5.4 & $\begin{array}{llll}3.245 & 0.499 & -0.112 & 0.081(\mathrm{M}) \\
2.983 & 0.511 & -0.043 & 0.071(\mathrm{~L})\end{array}$ \\
\hline $\mathrm{CuNCCrCN}\left(\mathrm{NH}_{3}\right)_{4}$ & none & TZVP & PW91 & 10.2 & 6.8 & $\begin{array}{llll}3.274 & 0.484 & -0.130 & 0.083(\mathrm{M}) \\
2.964 & 0.524 & -0.040 & 0.071(\mathrm{~L})\end{array}$ \\
\hline $\mathrm{CuNCCrCN}\left(\mathrm{NH}_{3}\right)_{4}$ & $\mathrm{COSMO}^{\mathrm{a}}$ & TZVP & PW91 & 7.7 & 5.2 & $\begin{array}{llll}3.318 & 0.488 & -0.140 & 0.082(\mathrm{M}) \\
3.001 & 0.529 & -0.048 & 0.070(\mathrm{~L})\end{array}$ \\
\hline $\mathrm{CuNCCr}(\mathrm{CN})_{5}$ & $\mathrm{COSMO}^{\mathrm{a}}$ & TZVP & PW91 & 7.3 & 4.8 & $\begin{array}{lllll}3.127 & 0.498 & -0.120 & 0.079(\mathrm{M}) \\
2.606 & 0.538 & -0.046 & 0.068(\mathrm{~L})\end{array}$ \\
\hline $\mathrm{CuNCCr}(\mathrm{CN})_{5}$ & $\mathrm{COSMO}^{\mathrm{a}}$ & TZVP & B3LYP & 4.6 & 3.1 & $\begin{array}{llll}3.216 & 0.590 & -0.117 & 0.074(\mathrm{M}) \\
2.776 & 0.630 & -0.056 & 0.062(\mathrm{~L})\end{array}$ \\
\hline
\end{tabular}

${ }^{\mathrm{a}}$ dielectric constant 80.4 (water), refraction index of the solvent 1.33 .

${ }^{\mathrm{b}}$ calculated using Mulliken (M) or Löwdin (L) spin-population analysis.

Mulliken spin populations on $\mathrm{Cu}^{\mathrm{II}}$ and $\mathrm{M}^{\mathrm{III}}\left(\mathrm{M}=\mathrm{Cr}^{\mathrm{III}}, \mathrm{Mn}^{\mathrm{III}}, \mathrm{Fe}^{\mathrm{III}}\right)$ are listed in Table $\mathrm{S} 2$.

Quite impressively broken-spin populations are calculated to be larger or equal than the high-spin one for all $\mathrm{M}^{\mathrm{III}}$, but with some exceptions for $\mathrm{Cu}^{\mathrm{II}}$. This observation is in accord with eq.19 and an the ferromagnetic Cu-M coupling. In Fig.S1 we plot the values of $n_{a} \cdot n_{b}$ $\mathrm{J}_{\mathrm{BS}}$ vs the function of the spin-density $\Delta$ defined by Ruiz et al(eq.20). ${ }^{14}$ A clear correlation $\left(\mathrm{n}_{\mathrm{a}} \cdot \mathrm{n}_{\mathrm{b}} \mathrm{J}_{\mathrm{BS}} 80.630 \Delta+6.502\right.$, standard deviation $\left.=2.55\right)$ is obeyed as discussed in the text. However large deviations from the correlation line come to show that a more detailed account of the spin-distributions within the $\mathrm{M}(\mathrm{CN})_{6}{ }^{3-}$ unit with unpaired spin density on the bridging $\mathrm{CN}$ - has to be made. 
Table S2. Spin densities on $\mathrm{Cu}^{\mathrm{II}}$ and $\mathrm{M}^{\mathrm{III}}\left(\mathrm{M}=\mathrm{Cr}^{\mathrm{III}}, \mathrm{Mn}^{\mathrm{III}}, \mathrm{Fe}^{\mathrm{III}}\right)$ in the $\mathrm{CuNCM}$ complexes (Figure 2) in their various high-spin (HS) and broken-spin (BS) ground and excited state electronic configurations. Values of $\mathrm{n}_{\mathrm{a}} \cdot \mathrm{n}_{\mathrm{b}} \mathrm{J}_{\mathrm{BS}}$ are also listed for the sake of comparison.

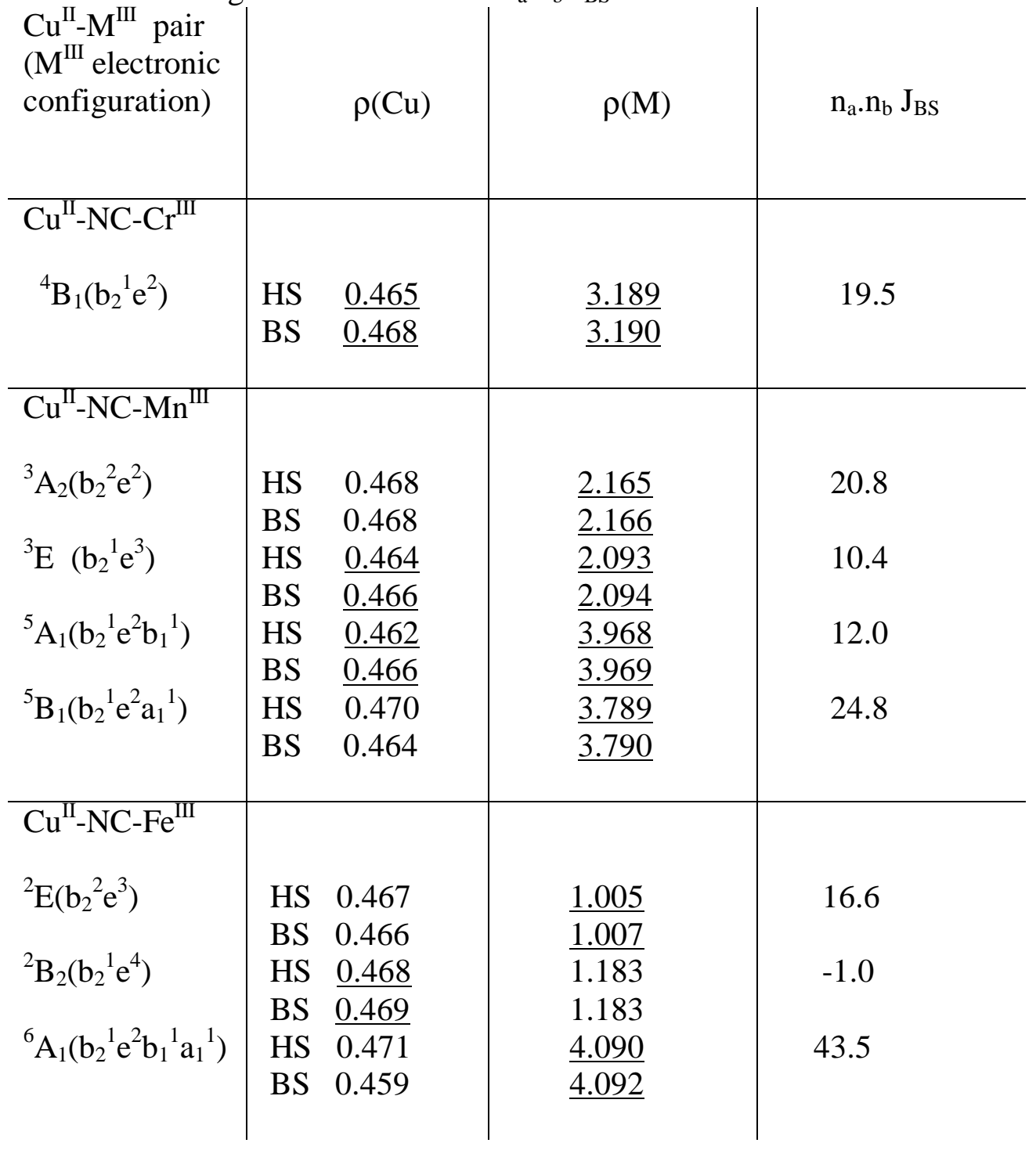




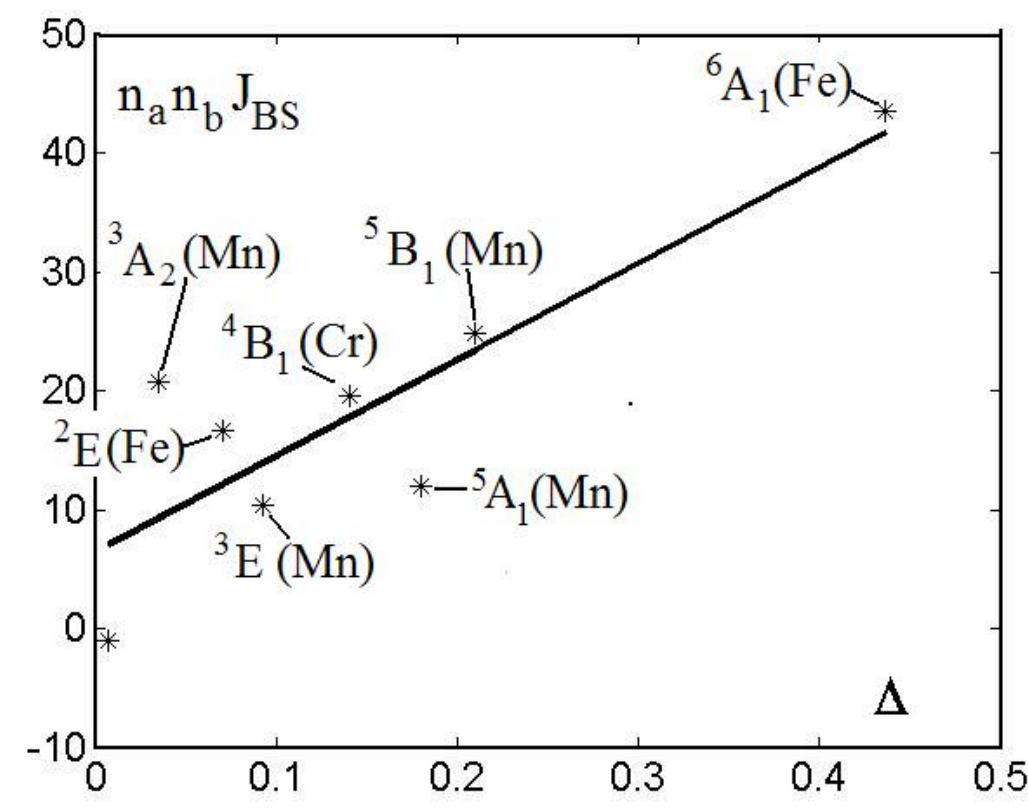

Fig.S1 The correlation between the values of $n_{a} \cdot n_{b} J_{B S}$ and the function of the spindensity $\Delta$ defined by Ruiz et al (eq.20, Ref.14). 
The $\mathrm{Cu}^{I I}-\mathrm{NC}-\mathrm{Fe}^{I I I}\left(\Gamma_{7}\right)$ exchange coupling

The ground state of the square planar $\mathrm{Cu}\left(\mathrm{NH}_{2} \mathrm{CH}_{3}\right)_{4}{ }^{2+}$ complex is non-degenerate with second order spin-orbit coupling contributions leading to a g-tensor anisotropy $\left(g_{z}>g_{x y}\right.$, typically $\left.\mathrm{g}_{\mathrm{z}}=2.25, \mathrm{~g}_{\mathrm{x}, \mathrm{y}}=2.05\right)$. The $\mathrm{Cu}^{\mathrm{II}}-\mathrm{Fe}^{\mathrm{III}}$ exchange coupling then can be calculated using the following non-Heisenberg spin-Hamiltonian:

$\mathrm{H}_{\mathrm{exc}}=-\mathbf{s}_{1} \mathbf{s}_{2} \mathbf{O}$

the $\mathbf{s}_{\mathbf{1}}$ and $\mathbf{s}_{\mathbf{2}}$ are spin vector operators acting on the $\mathrm{s}=1 / 2, \mathrm{~m}_{\mathrm{s}}= \pm 1 / 2$ spin functions of $\mathrm{Cu}^{\mathrm{II}}$ and $\mathrm{Fe}^{\mathrm{III}}$, respectively, while $\mathbf{O}$ is an orbital operator which acts on the $\mathrm{L}=1, \mathrm{M}_{\mathrm{L}}=0, \pm 1$ orbital functions on $\mathrm{Fe}^{\mathrm{III}}$. It is given by the following equation: ${ }^{1}$

$$
\begin{aligned}
& \mathbf{O}=\left(\mathbf{1}-\mathbf{l}_{z}^{2}\right) \cdot j_{z z}+\left(\frac{1}{2} \mathbf{l}_{z}^{2}+\frac{1}{2} \mathbf{l}_{x}^{2}-\frac{1}{2} \mathbf{l}_{\mathbf{y}}^{\mathbf{2}}\right) j_{x x}+\left(\frac{1}{2} \mathbf{l}_{z}^{2}-\frac{1}{2} \mathbf{l}_{x}^{2}+\frac{1}{2} \mathbf{l}_{\mathbf{y}}^{\mathbf{2}}\right) j_{y y}+\left(\mathbf{l}_{\mathbf{x}} \mathbf{l}_{z}+\mathbf{l}_{z} \mathbf{l}_{x}\right) j_{x z}+ \\
& \left(\mathbf{l}_{\mathbf{y}} \mathbf{l}_{z}+\mathbf{l}_{\mathbf{z}} \mathbf{l}_{\mathbf{y}}\right) j_{y z}+\left(\mathbf{l}_{\mathbf{x}} \mathbf{l}_{\mathbf{y}}+\mathbf{l}_{\mathbf{y}} \mathbf{l}_{\mathbf{x}}\right) j_{x y}
\end{aligned}
$$

with $\mathbf{l}_{\mathbf{z}}, \mathbf{l}_{\mathbf{x}}, \mathbf{l}_{\mathbf{z}}$ and $\mathbf{1}$ the representation of the $\hat{l}_{x}, \hat{l}_{y}, \hat{l}_{z}$ and $\hat{E}$ (identity) operators within the basis functions to $\mathrm{L}=1, \mathrm{M}_{\mathrm{L}}=1 \quad 0 \quad-1$. The $\mathrm{j}_{\mathrm{zz}}=\mathrm{J}\left({ }^{2} \mathrm{~B}_{2}\right) \mathrm{j}_{\mathrm{xx}}=\mathrm{j}_{\mathrm{yy}}=\mathrm{J}\left({ }^{2} \mathrm{E}\right)$ denote $\mathrm{Cu}-\mathrm{Fe}\left(\mathrm{d}_{\mathrm{xy}}\right)$, $\mathrm{Cu}-\mathrm{Fe}\left(\mathrm{d}_{\mathrm{yz}}\right)$ and $\mathrm{Cu}-\mathrm{Fe}\left(\mathrm{d}_{\mathrm{xz}}\right)$ exchange coupling parameters (eq.4).

$$
\mathbf{l}_{\mathbf{x}}=\left[\begin{array}{ccc}
0 & \frac{1}{\sqrt{2}} & 0 \\
\frac{1}{\sqrt{2}} & 0 & \frac{1}{\sqrt{2}} \\
0 & \frac{1}{\sqrt{2}} & 0
\end{array}\right] ; \mathbf{l}_{\mathbf{y}}=\left[\begin{array}{ccc}
0 & \frac{-i}{\sqrt{2}} & 0 \\
\frac{i}{\sqrt{2}} & 0 & \frac{-i}{\sqrt{2}} \\
0 & \frac{i}{\sqrt{2}} & 0
\end{array}\right] ; \mathbf{l}_{\mathbf{z}}=\left[\begin{array}{ccc}
1 & 0 & 0 \\
0 & 0 & 0 \\
0 & 0 & -1
\end{array}\right] ; \mathbf{1}=\left[\begin{array}{ccc}
1 & 0 & 0 \\
0 & 1 & 0 \\
0 & 0 & 1
\end{array}\right] ;
$$


Taking the matrix elements of the operator (S1) within the basis build up from the $s=1 / 2$, $\mathrm{m}_{\mathrm{s}}= \pm 1 / 2$ spin-functions on $\mathrm{Cu}^{\mathrm{II}}$ and $\Gamma_{7}, \mathrm{~m}_{\mathrm{s}}{ }^{\prime}= \pm 1 / 2$, fictitious spin functions on $\mathrm{Fe}^{\mathrm{III}}$, explicitly:

$$
\begin{aligned}
& \phi_{1}=\left|s=\frac{1}{2}, m_{s}=\frac{1}{2}\right\rangle\left|\Gamma_{7}, m_{s}{ }^{\prime}=\frac{1}{2}\right\rangle \\
& \phi_{2}=\left|s=\frac{1}{2}, m_{s}=\frac{1}{2}\right\rangle\left|\Gamma_{7}, m_{s}{ }^{\prime}=-\frac{1}{2}\right\rangle \\
& \phi_{3}=\left|s=\frac{1}{2}, m_{s}=-\frac{1}{2}\right\rangle\left|\Gamma_{7}, m_{s}^{\prime}=\frac{1}{2}\right\rangle \\
& \phi_{4}=\left|s=\frac{1}{2}, m_{s}=-\frac{1}{2}\right\rangle\left|\Gamma_{7}, m_{s}{ }^{\prime}=-\frac{1}{2}\right\rangle
\end{aligned}
$$

leads after some lengthy but strigthforward algebra to the following exchange coupling matrix:

$$
\begin{array}{cccc}
\phi_{1} & \phi_{2} & \phi_{3} & \phi_{4} \\
\frac{1}{12}\left[2 J\left({ }^{2} E\right)-J\left({ }^{2} B_{2}\right)\right] & 0 & 0 & \frac{1}{6} J\left({ }^{2} B_{2}\right) \\
0 & -\frac{1}{12}\left[2 J\left({ }^{2} E\right)-J\left({ }^{2} B_{2}\right)\right] & \frac{1}{3} \delta J\left({ }^{2} E\right) & 0 \\
0 & \frac{1}{3} \delta J\left({ }^{2} E\right) & -\frac{1}{12}\left[2 J\left({ }^{2} E\right)-J\left({ }^{2} B_{2}\right)\right] & 0 \\
\frac{1}{6} J\left({ }^{2} B_{2}\right) & 0 & 0 & \frac{1}{12}\left[2 J\left({ }^{2} E\right)-J\left({ }^{2} b\right.\right.
\end{array}
$$

In the exchange matrix (S5) we accounted for the particular case, where in addition of the strong axial field, there is an additional orthorhombic field. The latter would split $\mathrm{J}\left({ }^{2} \mathrm{E}\right)$ into $\mathrm{J}\left({ }^{2} \mathrm{E}\left(\mathrm{d}_{\mathrm{yz}}\right)\right)$ and $\mathrm{J}\left({ }^{2} \mathrm{E}\left(\mathrm{d}_{\mathrm{xz}}\right)\right)$

$\mathrm{J}\left({ }^{2} \mathrm{E}\left(\mathrm{d}_{\mathrm{yz}}\right)\right) \neq \mathrm{J}\left({ }^{2} \mathrm{E}\left(\mathrm{d}_{\mathrm{xz}}\right)\right)$ 
Then $\mathrm{J}\left({ }^{2} \mathrm{E}\right)$ and $\delta J\left({ }^{2} E\right)$ in eq.(S6) have to be substituted by their average and their difference, respectively:

$$
\begin{aligned}
& \mathrm{J}\left({ }^{2} \mathrm{E}\right)=\left[\mathrm{J}\left({ }^{2} \mathrm{E}\left(\mathrm{d}_{\mathrm{yz}}\right)\right)+\mathrm{J}\left({ }^{2} \mathrm{E}\left(\mathrm{d}_{\mathrm{xz}}\right)\right] / 2 ;\right. \\
& \delta \mathrm{J}\left({ }^{2} \mathrm{E}\right)=\left[\mathrm{J}\left({ }^{2} \mathrm{E}\left(\mathrm{d}_{\mathrm{yz}}\right)\right)-\mathrm{J}\left({ }^{2} \mathrm{E}\left(\mathrm{d}_{\mathrm{xz}}\right)\right] / 2 ;\right.
\end{aligned}
$$

Turning back to the CuNCFe exchange coupling with purely axial symmetry and vanishing $\mathrm{J}\left({ }^{2} \mathrm{~B}_{2}\right)$ parameter the matrix $\mathrm{S} 5$ takes the diagonal form

$$
\left[\begin{array}{cccc}
\phi_{1} & \phi_{2} & \phi_{3} & \phi_{4} \\
\frac{1}{6} J\left({ }^{2} E\right) & 0 & 0 & 0 \\
0 & -\frac{1}{6} J\left({ }^{2} E\right) & 0 & 0 \\
0 & 0 & -\frac{1}{6} J\left({ }^{2} E\right) & 0 \\
0 & 0 & 0 & \frac{1}{6} J\left({ }^{2} E\right)
\end{array}\right]
$$

It can then easily be shown that the degenerate $\phi_{2}$ and $\phi_{3}$ functions correspond to the total (effective) $\mathrm{M}_{\mathrm{s}}= \pm 1$ value, while both $\phi_{1}$ and $\phi_{2}$ belong to $\mathrm{M}_{\mathrm{s}}=0$, one stemming from the triplet, $S=1$, the other from the singlet, $S=0$.

The comparison of the matrix (S5) with the one that results from the application of the phenomenological Hamiltonian (eq.17) on the $S=1\left(M_{s}= \pm 1,0\right)$ and $S=0$ spineigenfunctions (eq. 18, eq. (S9)) yields immediately the parameters on the anisotropic 


$$
\left[\begin{array}{cccc}
\frac{3}{4} J & 0 & 0 & 0 \\
0 & -\frac{1}{4} J+\frac{1}{3} D & 0 & 0 \\
0 & 0 & -\frac{1}{4} J+\frac{1}{3} D & 0 \\
0 & 0 & 0 & -\frac{1}{4} J-\frac{2}{3} D
\end{array}\right]
$$

Hamiltonian given by eqs.(19).

\section{References}

1. M.Atanasov, C.Daul, H.U.Güdel, in Computational Chemistry, Reviews of Current Trends, J.Leszczynski, Ed. World Scientific, 2005, p.153-194. 